\title{
Study on optimization experiment and characteristic test of biomass granule forming machine
}

\author{
Heng Wang ${ }^{1}$, Shukun $\mathrm{Cao}^{1, *}$,Xiangwen Song ${ }^{1}$, Hao Shen $^{1}$, Yi Cui ${ }^{1}$, Zijian Cao ${ }^{1}$, shuqiang $\mathrm{Xu}^{1}$ \\ ${ }^{1}$ School of Mechanical Engineering, University of Jinan, Jinan 250022, Shandong Province, China
}

\begin{abstract}
According to the biomass pellet fuel forming machine, problems such as high energy consumption, easy clogging, and low efficiency exist in the granulation process. In this paper, corn and wheat stalks are used as raw materials to study the effects of the size of the raw materials and the moisture content on the formation rate, particle average length, particle density, mechanical durability, and heating value of the particulate fuel. The influence of parameters such as spindle speed and die diameter on the productivity, molding rate, mechanical durability, and particle density of the molding machine was investigated. Compressor and ANSYS were used to study the compression characteristics and flow characteristics of corn stalk, and the characteristics of the pellets were determined. The results showed that the corn stalk with a grain size of $4 \mathrm{~mm}$ with a moisture content of $14 \%$ and wheat straw with a grain size of $4 \mathrm{~mm}$ with a moisture content of $15 \%$ had high molding rate, good particle density, and good mechanical durability.
\end{abstract}

\section{Introduction}

With the rapid development of social economy, We rely on the energy more and more serious, However, the traditional energy damage the environment, a large number of pollutants in dire need of the development and utilization of a kind of renewable clean energy. Biomass is the only renewable source of carbon stored in solar energy. In total, zero emissions are achieved ${ }^{[1]}$, which can be used as a good fuel for industrial boilers, heating furnaces, and rural boilers, and can also be used as a clean fuel for power plants ${ }^{[2]}$.However, the energy consumption of biomass granule fuel moulding machine in the process of granulation is prevalent.

At present, the forming mechanism of grain process only on a certain technical parameters or the machine a parameter study on corn straw as raw material for molding machine main parameters of process parameters of the material and the ${ }^{[3,4]}{ }^{[5]}$ less at the same time, research literature. In this article to research the corn straw as raw material, raw material grinding particle size and moisture content of pellet fuel forming rate, average particle length, grain density, mechanical durability, the influence law of calorific value, the molding machine parameters such as spindle speed, die hole diameter on productivity, forming rate, the influence of mechanical durability and grain density ${ }^{[6]}$.It provides theoretical basis for pulverization, compression and granulation of straw in the preparation of material particles.

\section{Materials and Methods}

\subsection{Test materials and equipment.}

The trial raw materials wheat and corn stalks were taken from Zhangzhou area, Using the flat model biomass granule fuel forming mechanism is shown in figure 1 . Work when the motor through reducer drive roller rotation, biomass particles through raw material and the friction between the roller clamp into, extrusion, at last, through continuous extrusion die, finally through the knife cut into particles. Molding machine press roller clearance, spindle speed and other adjustable, die hole diameter can be changed by changing the pressure template.

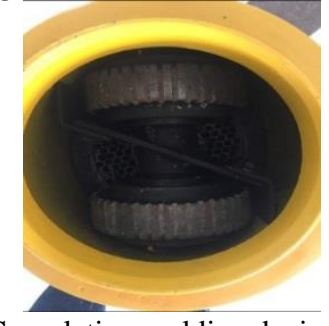

Fig.1 Granulation molding device

\subsection{The experimental method}

\subsubsection{The experiment to prepare}

Through this article we will maize straw crusher crushing, through changing grinder screen, selection of raw material particle size is according to the grinding particle size will be divided into three levels (size of $3 \mathrm{~mm}, 4 \mathrm{~mm}, 5 \mathrm{~mm}$ respectively), and according to the moisture content of

\footnotetext{
* Corresponding author: 87756997@qq.com 
different it is divided into three grades (moisture content $14 \%, 18 \%$ and $22 \%$, respectively). The grouping of straw after crushing is shown in Fig. 2 and Fig. 3.Through invt inverter control the frequency of the three-phase squirrelcage motor, by changing the inverter frequency control spindle speed $(1.0,1.4,1.8)$, and by changing the change of flat die hole diameter $(6 \mathrm{~mm}, 8 \mathrm{~mm}, 10 \mathrm{~mm})$.

\subsubsection{The experiment indicators and method}

(1)Productivity: we receive and weigh biomass particle in discharging port when Biomass pellet granulator is working every $10 \mathrm{~min}$. The calculating formulal is:

$$
Q=3600 \frac{m(1-H)}{(1-0.2) \times t}
$$

Where Q- productivity, $\mathrm{kg} / \mathrm{h}$

$\mathrm{m}$ - the sample quality, $\mathrm{kg}$

$\mathrm{H}$ - the molding fuel moisture content, $\%$

t- Pick up the sample time, $\mathrm{s}$

(2) Forming rate: using vibration sieve machine to screen and weigh, Calculating formula:

$$
X=100 \% \times \frac{m_{a}}{m_{b}}
$$

in the formula:

$\mathrm{X}$ - forming rate, $\%$

$\mathrm{m}_{\mathrm{a}}$-biomass pellet quality on the vibration sieve machine, $\mathrm{kg}$

$\mathrm{m}_{\mathrm{b}}$ - the total quality, $\mathrm{kg}$

(3)Mechanical durability: using vibration sieve machine to screen, then using drum machine directional operation to take out the samples, Calculating formula:

$$
C=\frac{m_{2}}{m_{1}} \times 100 \%
$$

in the formula:

C- granular mechanical durability, $\%$

$\mathrm{m}_{2}$ - biomass pellet quality on the vibration sieve machine after rotation, $\mathrm{kg}$

$\mathrm{m}_{1}$ - the total quality, $\mathrm{kg}$

(4)Grain density: According to the principle of Archimedes drainage, we use the electronic balance to measure data directly.

\subsubsection{Design of experiment}

According to the orthogonal test of corn straw raw material grinding particle size and moisture content of pellet fuel forming rate, average particle length, the law of the influence of the particle density and molding machine parameters such as spindle speed, die hole diameter on productivity, the influence of forming rate, particle density, etc, through the test, measurement formula deduce particles mechanical durability, the rule of calorific value.

\section{The results and discussion}

The orthogonal test results of two factors of corn and wheat straw were shown in Fig 2 and Fig 3.The results of

\begin{tabular}{|c|c|c|c|c|c|}
\hline $\begin{array}{l}\text { Test } \\
\text { unmber }\end{array}$ & $\begin{array}{l}\text { Crushing } \\
\text { particle } \\
\text { sice } \\
\text { (nim) }\end{array}$ & $\begin{array}{l}\text { Moisture } \\
\text { content } \\
(\%), .\end{array}$ & $\begin{array}{c}\text { Formin } \\
\mathbf{g} \text { rate } \\
(\%) .\end{array}$ & $\begin{array}{l}\text { Averara } \\
\text { particle } \\
\text { length } \\
\text { (mam) }\end{array}$ & 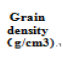 \\
\hline 1.. & 4. & 14. & 92.2. & 20. & 1.12 \\
\hline 2.. & 4. & 22.. & 83.3. & 18. & 1.01. \\
\hline 3. & 4. & 18. & 87.6. & 19. & 1.07 \\
\hline 4. & 3. & 14. & 94.4. & 21. & 1.17 \\
\hline s. & 3. & 22. & 85.6. & 19. & 1.05 \\
\hline 6. & 3. & 18. & 89.3.. & 20. & 1.09 \\
\hline 7. & 5. & 14. & 90.1.. & 19. & 1.14 \\
\hline 8. & s. & 22. & 8o. & 17. & 1.02 \\
\hline 9. & 5. & 18. & 85.6. & 18. & 1.06 \\
\hline
\end{tabular}
the orthogonal test of the two factors of the molding machine parameters are shown in Fig 4.

\begin{tabular}{|c|c|c|c|c|c|}
\hline $\begin{array}{c}\text { Test } \\
\text { number }\end{array}$ & $\begin{array}{l}\text { Crushing } \\
\text { particle } \\
\text { size } \\
\text { ( } \mathrm{mm})\end{array}$ & $\begin{array}{c}\text { moisture } \\
\text { content } \\
(\%,)^{2}\end{array}$ & $\begin{array}{l}\text { Forming } \\
\text { rate (\%) }\end{array}$ & $\begin{array}{l}\text { Average } \\
\text { particice } \\
\text { length } \\
\text { (mm) }\end{array}$ & $\begin{array}{l}\text { Grain density } \\
(\mathrm{g} / \mathrm{m} 3)^{-3}\end{array}$ \\
\hline 1 & 40 & 140 & $87.2 \%$ & 16 & $1.31 \%$ \\
\hline 2 & 40 & 22 & $80.7 \%$ & 140 & 1.12 \\
\hline 3 & 4 & 18 & 82.2 & 15 & 1.24 \\
\hline 4 & 3 & 14 & 90.60 & $17 \%$ & 1.35 \\
\hline 5 & 3 & $22 \%$ & 81.4 & 15 & 1.18 \\
\hline 6 & 3 & 18 & 85.20 & 16 & 1.24 \\
\hline 70 & 50 & 14 & 86.60 & 14 & 1.29 \\
\hline 8 & 5 & $22 \%$ & $78.3 p$ & 13 & 1.18 \\
\hline 9 & 5 & 18 & $81.5 \%$ & 15 & 1.26 \\
\hline
\end{tabular}

Fig 2. Two-factor Three Level Orthogonal Test of Corn Straw Raw Materials

Fig 3. Two-factor Three Level Orthogonal Test of Wheat Straw Raw Materials

The following conclusion is obtained by orthogonal experiment:

(1)When corn and wheat straw are under the same size, the moisture content is more higher, the particle granulating ratio and average particle length are more smaller, grain density decrease. Under the same moisture content, the particle size is more larger, the grain rate is more smaller, the grain average length is more shorter, grain density decrease. Mechanical durability of particles (crush resistance) is increased along with the increase of moisture content, has nothing to do with the particle size. Biomass particles combustion calorific value is related to the fuel type, has nothing to do with the size and moisture content.

(2) Under the same experimental condition, the forming rate of wheat straw was not as high as that of corn straw, and the cost of forming wheat straw was much higher than that of maize straw. In the same raw material, the particle size (particle size) of the raw material is easier to take shape, and the higher the granulation rate of biomass particles, the higher the particle density. In the same raw material, the higher the moisture content, the easier it is to form, the granule density will decrease, the particle size will be smaller, and the particles will be burnt. 


\begin{tabular}{|c|c|c|c|c|c|}
\hline $\begin{array}{c}\text { Test } \\
\text { number. }\end{array}$ & $\begin{array}{l}\text { Spindle } \\
\text { speed } \\
(\mathrm{m} / \mathrm{s})\end{array}$ & $\begin{array}{c}\text { Die hole } \\
\text { hole } \\
\text { diameter } \\
\text { ( } \mathrm{mm})\end{array}$ & $\begin{array}{c}\text { product } \\
\text { ivity } \\
(\mathbf{k g}) .\end{array}$ & $\begin{array}{l}\text { Formi } \\
\text { ng } \\
\text { rate } \\
(\%) .\end{array}$ & $\begin{array}{l}\text { Grain } \\
\text { density } \\
\left(\mathrm{g} / \mathrm{cm}^{3}\right)\end{array}$ \\
\hline 1. & 1.8 & 8. & 148.95. & 91.7. & 1.12. \\
\hline 2., & 1.8 & 10. & 156.36. & 86.7. & 1.01 \\
\hline 3. & 1.8 & 6. & 140.12 & 92.1. & 1.07 \\
\hline 4. & 1. & 8. & 150. & 88.6. & 1.15 \\
\hline 5. & 1.. & 10. & 154.56 & 87.4. & 1.04 \\
\hline 6. & $1 .$. & 6. & 148.24. & 90.2. & 1.09 \\
\hline 7. & 1.4 & 8. & 160.52 & 91.6. & 1.17 \\
\hline 8. & 1.4 & 10. & 164.92 & 89.2. & 1.07 \\
\hline 9. & 1.4 & 6. & 155.33. & 93.2. & 1.12 \\
\hline
\end{tabular}

Fig 4. Molding machine parameters two-factor three level orthogonal test

The following conclusions are obtained through the orthogonal experiment: the molding rate of maize straw is mainly determined by the spindle speed, which increases with the first decrease of the spindle speed. In the test range, the productivity of biomass particles increases with the increase of the diameter of the die hole, and the granule is easier to form. The mechanical durability of the corn biomass particles was increased with the increase of spindle speed, and the increase of the diameter of the die was firstly increased and then decreased. The energy consumption of tons has nothing to do with spindle speed and die diameter.

\section{Conclusion}

(1)As usual, when the particle size of corn straw is $4 \mathrm{~mm}$ and the moisture content is $14 \%$, and the particle size of wheat straw is $4 \mathrm{~mm}$, and the moisture content is $15 \%$,we can obtain a high molding rate, good grain density and good mechanical durability of the particles.

(2) Particles forming density is associated with the rotational speed of spindle, the greater the spindle speed is, the lower the rate of pellet formation is. When the die hole diameter is $8 \mathrm{~mm}$ and speed is $1.4 \mathrm{~m} / \mathrm{s}$, we can obtain the highest productivity, good grain density and forming rate for the Biomass granule machine.

(3)The wheat straw molding rate is lower than that of corn straw molding rate, but the wheat straw molding cost is far higher than that of maize straw.
(4)When the straw raw material is closer to the roller, the stronger the liquidity of particles is.

\section{Acknowledgements}

Fund Project: 1. Shandong Province, the major project of science and technology (item number: 2015ZDZX10001) $"$ the development and industrialization demonstration of intelligent corn combine harvester". 2. Taishan industry leading talent project special funds. 3. Shandong agricultural machinery equipment research and development innovation project.

\section{References}

1. Chen Zhengyu, Study on the parameters of biomass forming process[D]. Institute of mechanical science research, 2013.

2 Zhong Dongning,He Qingliang,Cai Zhengda,Yang Xiaoying. Study on automatic control system of biomass gasification power generation. [J] Electric automation. 2016,38(02):95-99.

3. Qu Jianjun,Zu Yakun,Zheng Yang,Duan Yuanli. Analysis of key parameters of row - hole biomass flat die machine[J]. Renewable energy, 2015,33(05):801806.

4. Hao Ling,Zu Yu,Dong Liangjie. Advances in the research of the molding technology and equipment of die - roll biomass fuel [J]. Anhui agricultural science, 2012,40(01):367-369+372.

5. Zhang Yitian. The process of biomass granule was studied by using rice husk and sawdust $[\mathrm{J}]$. Liaoning forestry technology,2012(03):17-18.

6. Kong Fanting. Experimental research and analysis on the properties of corn straw leaf and its granulation mechanism[D]. Northeast agricultural university, 2015. 